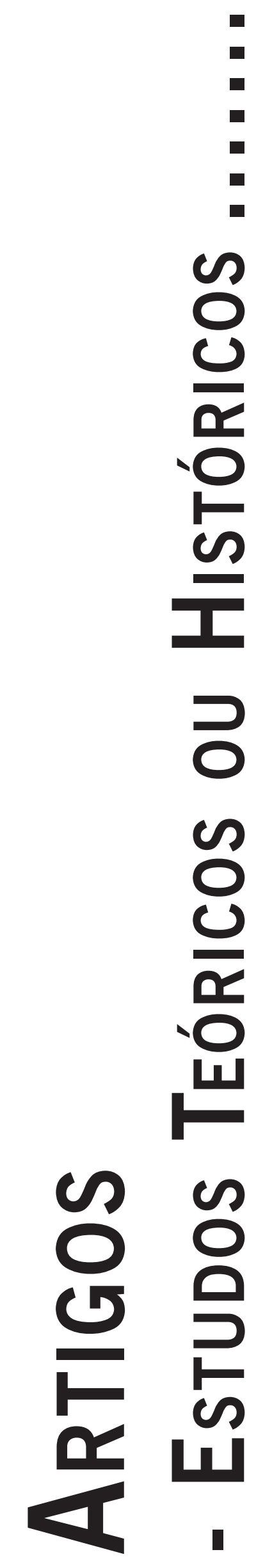




\title{
ARTHUR TATOSSIAN: UM ESTUDO BIOGRÁFICO
}

\author{
Arthur Tatossian: A Biographical Study \\ Arthur Tatossian: Un Estudio Biografico
}

LUCAS BLOC

VIRGINIA MOREIRA

\begin{abstract}
Resumo: Este artigo consiste em um estudo biográfico que tem como objetivo apresentar a trajetória histórica e bibliográfica de Arthur Tatossian (1929-1995. Psiquiatra francês de origem armênia, Tatossian pode ser considerado um dos principais representantes contemporâneos da tradição da psicopatologia fenomenológica. Considerando relevante um retorno aos elementos biográficos e influências teóricas que possibilitaram a construção de um já reconhecido modelo de psicopatologia fenomenológica, relatamos a história de vida de Tatossian, exposta em algumas de suas publicações e em homenagens póstumas, bem como apresentamos uma lista das produções relacionadas com a psiquiatria e com a psicopatologia fenomenológica. Além disso, apontamos algumas influências teóricas, como Husserl, Heidegger e Merleau-Ponty, autores da fenomenologia filosófica, e Binswanger, Tellenbach e Blankenburg, psiquiatras fenomenólogos com quem Tatossian manteve um diálogo constante. Por fim, apresentamos algumas perspectivas atuais como fruto do seu pensamento em países como França, Itália e Brasil. Tatossian desenvolveu um modelo de psicopatologia fenomenológica a partir da clínica e para a clínica, tendo sempre como preocupação fundamental o cuidado com a pessoa em sofrimento e o desenvolvimento de uma teoria que não se desvinculasse da prática, mantendo sempre um caráter eminentemente fenomenológico.
\end{abstract}

Palavras-chave: Arthur Tatossian; Psicopatologia fenomenológica; Estudo biográfico.

Abstract: This article consists of a biographical study which aims at presenting the historic and bibliographic trajectory of Arthur Tatossian (1929-1995). French psychiatrist of Armenian origin, Tatossian may be considered one of the most important contemporary representatives of the Phenomenological Psychopathology Tradition. Considering the relevance of a return to biographical elements and theoretical influences which brought about the construction of an already recognized model of phenomenological psychopathology, we have presented an account of Tatossian's history, as displayed in some of his publications and in posthumous tributes. In addition, we have pointed out some theoretical influences such as Husserl, Heidegger and Merleau-Ponty, philosophical phenomenology authors, and Binswanger, Tellenbach and Blankenburg, phenomenologist psychiatrists with whom Tatossian kept constant dialogue. Finally, we have presented some current perspectives which are fruit of his thinking in countries such as France, Italy and Brazil. Tatossian developed a phenomenological psychopathology model with the clinic as a starting point and final destination as well. His fundamental concern was always the caring of suffering patients and the development of a theory which was not disconnected from practice while always maintaining an imminently phenomenological character.

Keywords: Arthur Tatossian; Phenomenological psychopathology; Biographical study.

Resumen: Esto articulo consiste en un estudio biográfico que ten como objetivo presentar la trayectoria histórica y bibliográfica de Arthur Tatossian (1929-1995). Psiquiatra francés de origen armenia, Tatossian puede ser considerado uno de los principales representantes contemporáneos de la tradición de la psicopatología fenomenológica. Considerando relevante un retorno a los elementos biográficos y influenzas teóricas que posibilitaran la construcción de un ya reconocido modelo de psicopatología fenomenológica, relatamos la historia de vida de Tatossian, expuesta in algunas de suyas publicaciones y homenajes póstumas, bien como presentamos una lista de las producciones relacionadas con la psiquiatría y con la psicopatología fenomenológica. Además, apuntamos algunas influenzas teóricas, como Husserl, Heidegger y Merleau-Ponty, autores de la fenomenología filosófica, y Binswanger, Tellenbach y Blankenburg, psiquiatras fenomenólogos con los cuales Tatossian mantiene un dialogo constante. Por fin, presentamos algunas perspectivas actuales como fruto de suyo pensamiento in países como França, Itália y Brasil. Tatossian desenvolvió un modelo de psicopatología fenomenológica partiendo de la clínica y para la clínica, tiendo siempre como preocupación fundamental lo cuidado con la persona in sufrimiento y lo desenvolvimiento de una teoría que no se desvinculase de la práctica, manteniendo siempre un carácter eminentemente fenomenológico.

Palabras clave: Arthur Tatossian; Psicopatología fenomenológica; Estudio biográfico. 


\section{Introdução}

Psiquiatra francês de origem armênia, Arthur Tatossian (1929-1995) pode ser considerado um dos principais representantes contemporâneos da tradição da psicopatologia fenomenológica, incitando reflexões acerca do adoecimento mental, da compreensão dos diferentes fenômenos psicopatológicos e das diferentes práticas clínicas psicológicas e psiquiátricas.

Tatossian possui 279 publicações espalhadas em diversas revistas de grande e pequeno porte e livros que têm sua publicação restrita, em sua grande maioria na França. Deste total, 71 publicações são no campo da psiquiatria e da psicopatologia fenomenológica. Em português, existem atualmente traduzidos três artigos sobre cultura - sendo "Culturas e psiquiatria” (1978/2001), "Sintoma e cultura: algumas observações” (1985/2001) e "Cultura e psicopatologia: um ponto de vista fenomenológico” (1992/2001) -, o livro A Fenomenologia das Psicoses (1979/2006), principal obra de Tatossian, e a primeira parte do livro Clínica do Lebenswelt: Psicoterapia e psicopatologia fenomenológica (2012), que contém os seguintes artigos que foram transformados em capítulos do livro: "Fenomenologia da depressão" (de 1975), "A fenomenologia existencial e o inconsciente: um ponto de vista fenomenológico" (de 1978), "Aspectos fenomenológicos do tempo humano em psiquiatria” (de 1979), “Teoria e prática em psiquiatria: sintoma e fenômeno, um ponto de vista fenomenológico" (de 1980), "Fenomenologia do corpo" (de 1982), "Depressão, vivido depressivo e orientação terapêutica" (de 1983), "Fenomenologia da esquizofrenia" (de 1984), “O que é a clínica?" (de 1989) e "A fenomenologia: uma epistemologia para a psiquiatria?” (de 1996).

Tatossian sofreu influência e desenvolveu estudos a partir dos principais representantes da fenomenologia filosófica como Husserl, Heidegger, Sartre, Merleau-Ponty e Scheler, além dos autores da psicopatologia fenomenológica como Minkowski, Binswanger, Tellenbach, Van Den Berg, Blankenburg, Kimura, entre outros (Moreira, 2011; Tatossian \& Samuelian, 2002/2006).

Segundo Jeanne Tatossian e Samuelian (1979/2006), Tatossian foi especialmente reconhecido pelo papel que a fenomenologia desempenhava na sua prática cotidiana e nas relações que estabelecia com os profissionais e com os pacientes. Compreende que a fenomenologia não é uma aplicação banal da teoria filosófica; é antes uma forma de "questionar" e de buscar compreender o doente mental. Trata-se de um grande esforço clínico que jamais poderia se resumir a receitas, pois isto conduziria a uma falsa fenomenologia. Esta é a via que Tatossian segue ao trazer a fenomenologia para o campo da clínica e da psicopatologia.

Este artigo consiste em um estudo biográfico que tem como objetivo apresentar a trajetória histórica e bibliográfica de Arthur Tatossian, bem como apontar elementos que permitiram a construção de sua psicopatologia feno- menológica. Para tanto, como procedimento de pesquisa, fizemos um levantamento das obras de Tatossian, buscando relatos sobre a produção científica e da sua história de vida, tendo encontrado nos prólogos e prefácios de seus livros a descrição tanto do papel e da relevância de seu pensamento fenomenológico quanto do trabalho clínico cotidiano, testemunhado por colegas de trabalho e alunos. Além disso, tivemos acesso a uma edição da revista francesa na revista La Lettre de Psychiatrie Française, Caïn (1995) em homenagem a Tatossian sobre fenomenologia e psiquiatria em que são dados alguns depoimentos e também a carta enviada para Virginia Moreira pela viúva de Artur Tatossian, Jeanne Tatossian, publicada como prefácio do livro Clínica do Lebenswelt: Psicoterapia e psicopatologia fenomenológica (2012).

\section{Vida e obra}

Arthur Tatossian nasceu em 3 de abril de 1929 em Marselha, filho de pais armênios que, em 1921, imigraram para a França em função das perseguições pelos turcos. Como para a maioria das famílias de imigrantes, a vida não foi fácil, mas eles guardavam um grande desejo de se integrar à população francesa. Pode-se dizer que, apesar das dificuldades, Tatossian teve uma infância feliz no plano afetivo. Começou a ler por volta dos seis anos e desde cedo principiou a devorar os livros a que tinha acesso. Entre nove e dez anos frequentava assiduamente bibliotecas e suas qualidades intelectuais impressionavam desde muito cedo (Tatossian \& Samuelian, 2002/2006).

Na adolescência, Tatossian foi marcado pela morte de seu pai em 1943. Desde muito jovem, então, esteve diante de problemas materiais com os quais pôde compreender o papel fundamental do trabalho. Mesmo diante das dificuldades, os estudos eram sempre uma prioridade, muito embora ajudasse sua mãe no comércio, trabalhando uma parte da noite, e se contentasse com poucas horas de sono, hábito que manteve ao longo de sua vida. $\mathrm{O}$ segundo lugar no concurso geral de História em 1945 e o bacharelado em Filosofia em 1947, com 18 anos, foram algumas de suas conquistas, ainda no ensino secundário francês (Tatossian \& Samuelian, 2002/2006).

Em 1950 iniciou seus estudos especificamente médicos e em 1952 se tornou interno dos hospitais de Marselha. Nesse período, criou grandes laços de amizade e também se licenciou em ciências. Casou-se pela primeira vez em 1954. Em 1958 obteve a medalha de ouro dos Hospitais de Marselha, sendo, em seguida, nomeado Chefe de Clínica. Em 1960 se tornou médico dos Hospitais de Marselha e trabalhou junto ao professor Pierre Mouren, dividindo seu tempo entre a neurologia e a psiquiatria (Tatossian \& Samuelian, 2002/2006). Vale lembrar que, além dos trabalhos no campo da fenomenologia clínica, Tatossian possui várias publicações no campo da neurologia e neuropsiquiatria. 
De 1959 a 1967, foi encarregado do curso de Psicopatologia na Faculdade de Letras e Ciências Humanas de Aix-en-Provence e, em 1961, era responsável pelo curso de Neuropsiquiatria Infantil do Instituto de Biometria Humana e de Orientação Profissional. Em seguida, se tornou chefe dos Hospitais de Marselha, dirigindo o Serviço de Psiquiatria do Hospital SainteMarguerite em 1972 e sendo Médico-Chefe do $5^{\circ}$ setor de Bouches-du-Rhône. A partir de 1980, dirigiu o Serviço de Psiquiatria e de Psicologia Médica do Hospital de La Timone (Tatossian \& Samuelian, 2002/2006).

Em depoimentos realizados à revista La Lettre de Psychiatrie Française, Caïn (1995) afirma que, como psiquiatra, Tatossian trazia uma preocupação fundamental: considerar o homem na sua totalidade, demonstrando, para Arditti (1995) uma competência que transcendia o campo psiquiátrico, atingindo a psicologia, a filosofia e a fenomenologia. Embora preferisse a fenomenologia, se interessava também pela biologia, pela farmacologia e pela psicoterapia, pela clínica e também pela psicopatologia, além de outros campos de saber (Darcourt \& Tatossian, 1997). Este amplo conhecimento lhe rendeu grande popularidade na psiquiatria nos anos 70 e 80 (Dalle Luche, 2003).

São muitas as qualidades intelectuais que, associadas às qualidades humanas, geravam uma grande admiração daqueles que o rodeavam, mesmo sendo sua discrição algumas vezes pouco compreendida. Para Tatossian \& Samuelian (2002/2006),

Seu sentido de dever, sua probidade desenvolvida ao extremo, sua bondade real, sua prestatividade, suas faculdades de escuta do outro, são as qualidades que todos aqueles que se aproximaram de Arthur Tatossian lhe reconhecem e que faziam com que ele fosse muito respeitado e sempre admirado. (p. 352)

Jeanne Tatossian (2012), sua esposa, destaca o cuidado que ele tinha com os pacientes, estando sempre disponível sem se preocupar com o tempo das sessões ou mesmo com os honorários que tinha a receber. Recusava assumir a posição de mestre. Suas obras geraram grande admiração de psiquiatras estrangeiros e, em particular, dos japoneses que traduziram o livro La Phénoménologie des psychoses. Arthur Tatossian faleceu aos 66 anos, no dia 10 de junho de 1995, em decorrência de uma insuficiência respiratória grave que prejudicou bastante seus últimos anos de vida (Tatossian \& Samuelian, 2002/2006).

Para compreendermos o desenvolvimento teórico de Arthur Tatossian, é fundamental que se visualize sua obra como um todo e se identifique historicamente os diversos movimentos empreendidos. Em 1997, dois anos após sua morte, vários textos inéditos e pouco conhecidos foram editados e agrupados em um livro chamado Psychiatrie Phénoménologique. Este livro, pensado e montado por Guy Darcourt e por Jeanne Tatossian, possui um índice de todas as obras, que é adotado aqui como referencial para apresentar a estrutura da obra de Arthur Tatossian. Os trabalhos de Tatossian voltados para a psiquiatria e psicopatologia fenomenológica, que listamos neste artigo, datam de 1957 a 1996, abrangendo quase todo o período de produção do autor, em um total de 71 obras. Vale ressaltar que houveram outras produções voltadas para psiquiatria, psicossomática e psicologia - sendo 138 produções no período de 1955 a 1996; e para neurologia - 70 produções, a grande maioria em coautoria, no período de 1955 a 1973.

Com o objetivo de facilitar a visualização do conjunto da obra e a evolução do pensamento ao longo das décadas, optamos por dividi-la didaticamente em quatro períodos históricos, seguindo um critério puramente cronológico e referente às décadas em que foram produzidas as obras: 1) 1957-1970; 2) 1971-1980; 3) 1981-1990 e 4) 1991-1996. Ao longo da descrição dos períodos e das obras, daremos destaque àquelas que consideramos de maior reconhecimento e relevância.

No período de 1957-1970, Tatossian publicou sete trabalhos. Sua tese de doutorado, "Étude phénoménologique d'un cas de schizophrénie paranoïde", foi defendida em 1957 e é o primeiro estudo fenomenológico francês de um caso de esquizofrenia (Darcourt, 2002/2006; Darcourt \& Tatossian, 1997). Esta é uma obra densa e original, em que a Daseinsanálise foi utilizada em um momento em que era pouco conhecida na França. Durante o doutorado, Tatossian não tinha um orientador de tese, pois nenhum professor de medicina conhecia a fenomenologia profundamente, e realizou um trabalho solitário de leitura em alemão de Husserl, Heidegger, Binswanger e Kuhn, o que originou sua tese. A originalidade e qualidade da obra foram percebidas pela banca que, mesmo diante da dificuldade de apreciar o texto por envolver elementos ainda pouco estudados que entrelaçavam fenomenologia e psiquiatria, atribuiu menção de tese. Neste texto, Tatossian já demonstrava o domínio que tinha sobre os conceitos e sinalizava para alguns aspectos da fenomenologia que norteiam sua obra e anunciam de alguma forma a orientação das reflexões empreendidas durante seu percurso (Darcourt, 2002/2006; Darcourt \& Tatossian, 1997).

Este estudo de caso, que foi sua tese de doutorado, antes de ser publicado em 1997 no livro Psychiatrie Phénoménologique, estava apenas datilografado e era pouco difundido. Para Darcourt \& Tatossian (1997), ele é de grande importância histórica e bibliográfica por se tratar de um resumo do que viriam a ser suas principais referências e da sua concepção de psiquiatria fenomenológica, regida sob grande influência de Binswanger, apontado pelo próprio Tatossian como quem o fez penetrar na inspiração fenomenológica e existencial da ciência psiquiátrica, principalmente sob a forma da Daseinsanálise.

Também em 1957, anteriormente à tese, Tatossian escreveu um texto sobre a existência maníaca, "Ĺexistence maniaque", que é verdadeiramente seu primeiro trabalho 
fenomenológico. Dois anos depois, em 1959, publicou em uma revista de pequena circulação o artigo "Ĺapproche phénoménologique du fait hallucinatoire". Este texto é considerado importante pelo fato de poder encontrar elementos deste trabalho no La Phénoménologie des psychoses, sua principal obra, publicada em 1979, vinte anos mais tarde.

Nos anos seguintes, as publicações fenomenológicas foram raras, muito embora as discussões estivessem presentes na universidade e na formação dos seus alunos. De 1962 a 1965, foram escritos quatro textos - "Analyses phénoménologiques de la conscience delirante: l'Alter Ego et l'intersubjectivité" (1962-1963), com P. Mouren, P. Verne e M. Arditti; "Us et abus de la phénoménologie en psychiatrie” (1963-1964), também com com P. Mouren, P. Verne e M. Arditti; "Analyses phénoménologiques de la conscience délirante II - L’œuvre de conaissance” (19641965), com M. Arditti e E. Nicolai; e "Analyses phénoménologiques de la conscience délirante III - Le problème de L’Ego" (1964-1965). São três artigos abordando uma análise fenomenológica da consciência delirante e uma reflexão sobre o uso e abuso da fenomenologia em psiquiatria (Darcourt \& Tatossian, 1997). Vale ressaltar que até o início dos anos 1970, salvo os trabalhos aqui citados, incluindo sua monumental tese de doutorado sobre esquizofrenia, Tatossian escreveu a grande maioria dos textos sobre neurologia, atuando como neuropsiquiatra (Darcourt, 2002/2006).

Já no segundo período, de 1971 a 1980, Tatossian escreveu treze trabalhos de fenomenologia. Este período se inicia com um texto de 1973 em coautoria com Sébastien Giudicelli, seu aluno e sucessor no ensino de psiquiatria na Faculdade de Medicina de Marselha: "De la phénoménologie de Jaspers au 'retour à Husserl'. L'anthropologie compréhensive de Zutt et Kullenkampff”, no qual realiza um percurso que se inicia com a proposta de psicopatologia geral de Jaspers, retornando para a fenomenologia husserliana através, principalmente, de Binswanger, até chegar na antropologia compreensiva de Zutt e Kulenkampff.

Em seguida, publicou, em 1975, seu primeiro trabalho sobre depressão, "Phénoménologie de la dépression", traduzido para o português e publicado como capitulo no livro Clinica do Lebenswelt: Psicoterapia e psicopatologia fenomenológica (2012), em que fez um percurso histórico da compreensão fenomenológica da depressão e utilizou principalmente o olhar constitutivo de Binswanger para discutir esta psicopatologia. Posteriormente, publicou um texto sobre a aproximação fenomenológica ao vivido de pacientes com câncer, "Les structures existencielles chez lês cancéreux. Psychologie des limites ou limites de la psychologie?", em 1973, e um segundo trabalho, em 1977, sobre o sentido da depressão, "Le sens de la dépression".

Ainda destacamos neste período um texto que Tatossian escreveu em 1979 sobre o tempo humano em psiquiatria, "Aspects phénoménologiques du temps humain en psychiatrie", também traduzido para o portu- guês e publicado como capitulo, que já mostrava o lugar importante da temporalidade para compreensão do sujeito e da psicopatologia, e seu primeiro trabalho discutindo a questão da cultura e da psiquiatria, "Cultures et psychiatrie", escrito em 1978 e publicado como artigo em português em 2001 na Revista de Latinoamericana de Psicopatologia Fundamental. Foi neste período também que ele realizou reflexões sobre fenomenologia e psicanálise. Segundo Darcourt \& Tatossian (1997), diferentemente da maioria de seus contemporâneos, Arthur Tatossian optou pela fenomenologia ao invés da psicanálise; este era um tema polêmico e repleto de controvérsias, principalmente diante da predominância da psicanálise na França.

Após longo período de reflexão, Tatossian apresentou, em duas conferências, dois textos que discutem a questão do inconsciente na psicopatologia fenomenológica: "La phénoménologie existencielle et l'inconscient. Un point de vue psychiatrique", em 1978, traduzido para o português e publicado como capitulo de livro em 2012, e "Inconscient et phénoménologie", de 1979. Em 1978, publicou também um artigo sobre sintoma clínico e estrutura fenomenológica, "Symptôme clinique et structure phénoménologique", no qual desenvolveu suas primeiras discussões sobre o lugar do sintoma, do diagnóstico e sobre a experiência fenomenológica na psiquiatria. Estes são pontos de discussão centrais para Tatossian que estão diretamente ligados ao seu movimento de tentar sedimentar uma via fenomenológica, não apenas metodológica, na psiquiatria e na psicopatologia.

O ano de 1979 marcou uma virada na carreira de Tatossian, alavancada principalmente pela publicação do livro Phénoménologie des psychoses, considerado sua obra mestra. Publicado após o Congresso de Psiquiatria e Neurologia de língua francesa, e reeditado em 1997 pela editora Art du Comprendre, este texto, traduzido em japonês, italiano (2003) e português (2006), pela editora Escuta, se apresenta como uma espécie de compêndio da psicopatologia do século XX (Dalle Luche, 2003) e é considerado o mais importante trabalho fenomenológico sobre as psicoses realizado na França após a guerra (Darcourt, 2002/2006). Nesta obra, Tatossian passeia de forma crítica sobre as diversas compreensões fenomenológicas das psicoses e desenvolve também uma discussão epistemológica acerca da psicopatologia fenomenológica. Trata-se de um trabalho descritivo com um rigor primoroso e um nível de detalhamento pouco encontrado sobre o que se passa na experiência psicótica (Moreira, 2006).

Azorin, Naudin \& Pringuey (2002) escrevem no prefácio da terceira edição francesa que o Phénoménologie des psychoses "era uma espécie de bíblia retratando fielmente os trabalhos da quase-totalidade dos psiquiatras fenomenólogos existentes" (p. 9) e fez "renascer" a corrente fenomenológica na França que, neste período, se desenvolvia principalmente na Itália e na Alemanha. Em um período em que a psicanálise tinha um papel dominante, Tatossian é posto por Cabestan \& Dastur (2011) como 
um dos responsáveis por ter mantido aberta a via fenomenológica da psiquiatria na segunda metade do século XX. Com a escassez de trabalhos traduzidos na França, a condensação dos trabalhos fenomenológicos realizado por Tatossian neste livro ainda ganha mais importância neste momento histórico.

Além disso, para Azorin, Naudin \& Pringuey (2002), Phénoménologie des psychoses significa uma advertência para o mundo psiquiátrico contemporâneo, pois a psiquiatria estaria ignorando suas origens na experiência cotidiana e o mundo vivente sob o pretexto de objetividade e de positivismo. Para eles, Tatossian não faz simplesmente uma coleta das obras de outros autores, mas sim refaz passo a passo um caminho no campo fenomenológico. Após esta publicação, Tatossian passou a ser convidado para participar de congressos e colóquios, escrever artigos e seus textos passaram a ser valorizados por editores. Além disso, pode-se dizer que, depois de 1979, sua obra fenomenológica ganhou fôlego, passando a produzir seus trabalhos fenomenológicos mais profundos e bem-acabados, muito embora ainda não tivesse abandonado plenamente a psiquiatria geral (Darcourt, 2002/2006; Darcourt \& Tatossian, 1997).

O terceiro período (1981-1990) se inicia com a publicação de um texto sobre fenomenologia, linguística e psiquiatria, "Phénoménologie, linguistique et psychiatrie" e com a publicação em italiano de uma reflexão fenomenológica sobre a hipocondria, "Fenomenologia dell'ipocondria”, em 1981. O terceiro e o quarto textos específicos sobre depressão também foram escritos no início deste período, trazendo uma visão fenomenológica que diferencia depressão e tristeza, aproxima a depressão da questão do corpo vivido e discute as classificações dos estados depressivos através da depressividade como modo global do ser. São eles: "Phénoménologie de la depression", em 1981, e "Phénoménologie du corps, corps et depression”, em 1982.

Entre 1983 e 1985, Tatossian produziu onze textos que aproximam a fenomenologia de questões como psicose e câncer ("Psychose et cancer"), velhice ("Le vécu de la vieillesse”) e internamento psiquiátrico ("Le lit du malade psychique"), todos de 1983; família e instituição ("Famille et instituition: le sujet comme enjeu”); e uma ampla discussão sobre o Édipo em Kafka, Musil e Freud (“Oedipe en Cacanie: Kafka, Musil et Freud”), ambos produzidos em 1984.

O ano de 1984 é marcado pela publicação de seu segundo livro, La vie en faute de mieux, no qual discute a depressão, desde sua definição e classificação até possíveis terapêuticas. Segundo Darcourt \& Tatossian (1997), este era um livro que ele afirmava ser verdadeiramente sem pretensões, um estudo mais próximo da cotidianidade clínica e mais terapêutico, com uma linguagem menos acadêmica e mais acessível. Em 1985, Tatossian participou de um colóquio organizado por Pierre Fédida sobre fenomenologia, psiquiatria e psicanálise, em homenagem à Binswanger, onde apresentou uma comunicação sobre prática psiquiátrica e fenomenologia, "Pratique psychiatrique et phénoménologie”, que foi publicada nos anais em 1985, em um livro organizado por Pierre Fédida, em 1986, e, posteriormente, de forma completa, em 1997, nos seus textos reunidos (Darcourt \& Tatossian, 1997).

O final deste período foi atravessado ainda por produções que discutiam o conceito de psicose ("Le concept de psychose”), em 1986; os estados demenciais ("Phénoménologie des états démentiels"), em 1987; a temporalidade nos alcoólatras ("Sur quelques aspects de la temporalité chez l'alcoolique”), em 1988; o cotidiano ("Le jour, la nuit, le quotidien"), em 1989; a melancolia ("La subjectivité mélancolique”), escrito em 1988 e 1989; a fenomenologia e a análise existencial, com Jean-Michel Azorin ("Phénoménologie et analyse existentielle"), em 1990; classificação psiquiátrica ("Classification psychiatrique et phénoménologie”), também em 1990; entre outros. Ainda destacamos o texto de 1989, "Qu'est-ce que la clinique”, no qual ele discute o que é um trabalho clínico e de que forma os modelos perceptivos e inferenciais balizam a atividade clínica, texto publicado em português em 2012.

O quarto e último período (1991-1996), antes de sua morte, ainda se mostrou muito produtivo. No $1^{\circ}$ Congresso Internacional sobre as esquizofrenias e as psicoses afetivas, realizado em Genebra, em 1991, apresentou em um simpósio sobre a fenomenologia da esquizofrenia, uma comunicação sobre a nosologia da esquizofrenia, "La nosologie de la schizophrénie. Un point de vue phénoménologique”. Em seguida, convidado por Dominique Pringuey e pela Sociedade de Psiquiatria de Nice, apresentou, em 1992, uma conferência sobre cultura e psicopatologia, "Culture et psychopathologie. Un point de vue phénoménologique”, traduzido para o português e publicado como artigo em 2001. Neste mesmo período, revisitou a obra de Kraepelin, "Kraepelin revisité” e apresentou na IV Jornada de Psiquiatra de Toulon, em 1993, um texto sobre a separação e intersubjetividade, "Séparation et intersubjectivité".

Entre os textos deste período, destacamos um trabalho apresentado, em 1993, no Colóquio Europeu de Fenomenologia Clínica em Bruxelas, sobre a experiência do fenômeno e o projeto psicoterápico, "L’expérience du phénomène et le projet psychothérapique”. Neste texto, publicado postumamente em 1997, Tatossian discute a noção de fenômeno e as repercussões de tal concepção para o delineamento de um projeto psicoterápico. Publica ainda quatro trabalhos em 1994: sobre Ricœur - "L'identité humaine selon Ricœur et le problème des psychoses"; sobre o vivido de pacientes com câncer - "Le vécu des cancéreux: raison et déraison”, em 1994; sobre delírio - "Délire: sujet et subjectivité", também em 1994; e um texto importante e denso sobre subjetividade e fenomenologia -, "La subjectivité", inserido no Traité de psychopathologie de Daniel Widlöcher. Em 1995, ano da 
morte de Tatossian, publica um estudo sobre o escritor e dramaturgo sueco August Strindberg, que contempla também as discussões de Jaspers e Binswanger sobre o caso - "August Strindberg et le cas Strindberg".

Após a morte de Tatossian, foram publicados ainda mais cinco textos: sobre as condições de uma psicoterapia dos esquizofrênicos - "Les conditions aprioriques d'une psychothérapie des schizophrènes"; uma discussão sobre a fenomenologia como uma epistemologia para o psiquiatra, "La phénoménologie: une épistémologie pour le psychiatre", demarcando fortes posicionamentos sobre o lugar da fenomenologia no campo psiquiátrico, texto traduzido e publicado em 2012; um texto sobre a fenomenologia da paranóia - "Phénoménologie des paranoïas"; um verbete sobre fenomenologia com Jean-Michel Azorin em um manual de psiquiatria de 1996 - "Articles de la rubrique: Phénoménologie”; e seu último texto a ser escrito -, "Ĺinterpretation paranoïque", que seria apresentado em uma conferência prevista em Paris, o que foi impossibilitado pelo seu adoecimento.

Ao visualizarmos todo este material, podemos perceber o amplo desenvolvimento teórico de Tatossian, com uma diversidade que nos chama atenção. Suas principais e mais significativas publicações voltam-se para a psicopatologia fenomenológica, seja como ferramenta para compreender o outro e seu vivido patológico, seja para discutir os elementos que fazem parte de uma clínica fenomenológica situada no entrelaçamento entre teoria e prática.

\section{Influências e perspectivas: caminhos para uma clínica fenomenológica}

Tatossian tinha como preocupação fundamental ajudar aqueles que considerava mais importantes: os pacientes. A clínica e o contato com os pacientes eram para Tatossian uma Arte que tinha como premissa a compreensão de que "o doente é um ser que sofre e que o melhor a fazer é reconfortá-lo do que elaborar hipóteses, certamente muito sedutoras do ponto de vista intelectual, mas não muito úteis na prática cotidiana” (Tatossian \& Samuelian, p. 355). A partir disso, chegamos a um ponto importante que é a forma em que a fenomenologia, seja ela filosófica ou clínica, constitui o pensamento de Tatossian e a forma de compreender a doença e os doentes mentais.

Para Tatossian, uma abordagem fenomenológica não poderia ser entendida como um novo olhar que se integraria com outras abordagens psicopatológicas, mas sim como o próprio campo da experiência em si mesma, sendo validada somente por ela mesma em uma atitude de "ver", buscando uma lógica natural e intersubjetiva (Tatossian \& Samuelian, 2002/2006). Ou seja, é com uma atitude fenomenológica que se atinge esta experiência, o fenômeno da forma como se apresenta, sendo a teoria um aliado posterior importante para compreender o vivido do outro.
O pensamento de Tatossian foi marcado pela diversidade e por um movimento de sempre questionar a si mesmo e a própria experiência psiquiátrica. Ao longo de seus escritos, é possível apontarmos algumas influências de forma direta ou indireta na composição de suas obras. Azorin, Naudin e Pringuey ${ }^{1}$ (2002) consideram que o pensamento de Tatossian, no que diz respeito à influência da fenomenologia filosófica, é um constante vai-e-vem entre Husserl e Heidegger que sedimenta sua base epistemológica. Em Husserl, Tatossian encontraria um método progressivo de "des-construção"2 dos fenômenos que estruturam a vida mental. Já em Heidegger, encontraria os meios para o desenvolvimento de um olhar mais radical, que pretendia se distanciar de um caráter metafísico, ajudando a renunciar ao Ego, buscando situar de uma vez por todas, seu campo em uma análise existencial da cotidianidade e defendendo a necessidade de um contato constante com o paciente (Azorin, Naudin \& Pringuey, 2002).

Foi a aproximação entre a fenomenologia e a psiquiatria que possibilitou o desenvolvimento da psicopatologia fenomenológica. Autores da fenomenologia filosófica como Husserl, Heidegger e, mais tardiamente, MerleauPonty, foram referenciais fundamentais, influenciando, em alguns momentos de forma acessória e em outros momentos de forma direta (Tatossian, 1979/2006), os principais autores da psicopatologia fenomenológica. A psicopatologia fenomenológica pode ser caracterizada, de forma geral, pela tentativa de compreender os fenômenos psicopatológicos. Uma espécie de teorização acerca do vivido psicopatológico, uma ferramenta para a compreensão da experiência psicopatológica, do Lebenswelt (mundo vivido ou mundo da vida) do sujeito em sofrimento psíquico, e Tatossian defende uma compreensão fenomenológica da doença mental a partir de uma mudança de atitude que se dá no campo da clínica (Tatossian, 1979/2006).

Trata-se da passagem de uma atitude natural de compreensão da realidade como objetiva para uma atitude fenomenológica, abandonando justamente aquilo que se apreende como previamente estabelecido. Tal compreensão representa uma implicação filosófica de sempre trabalhar em fluxo, recusando prejulgamentos, permitindo o movimento da experiência fenomenológica; que esse vivido possa ser compreendido a partir do contato com a loucura e com o louco. Este conceito é importante na medida em que permite compreender o sujeito que está passando por uma experiência psicopatológica, mas também compreender a própria psicopatologia em uma espécie de co-experiência, objetiva e também subjetiva (Tatossian, 1979/2006).

Tatossian se aproximou de uma fenomenologia eminentemente existencial, que se sustenta sobre o conceito de Lebenswelt. Este é um conceito fundamental para

\footnotetext{
Estes autores foram alunos de Tatossian e são representantes atuais da psiquiatria fenomenológica na França (Cabestan \& Dastur, 2011). Termo utilizado pelos autores.
} 
a fenomenologia e que "interessa à psicopatologia fenomenológica em sua referência simultânea a Husserl e Heidegger" (Tatossian, 1979/2006, p. 87). Além disso, este é também considerado o eixo da fenomenologia existencial de Merleau-Ponty (Moreira, 2009). Reconhecemos a dupla importância de Husserl e Heidegger na composição da psicopatologia e da clínica fenomenológica de Arthur Tatossian, bem como de Merleau-Ponty, principalmente via conceito de Lebenswelt, o que nos levou a denominar seu pensamento como uma clínica do Lebenswelt (Tatossian \& Moreira, 2012).

Ele compreendia que a fenomenologia filosófica tinha como função inspirar um modelo de clínica (Tatossian \& Azorin, 1984). Ou seja, não se tratava de simplesmente aplicar conceitos filosóficos clinicamente, mas sim utilizá-los como inspiração para a construção de uma clínica fenomenológica. É importante sublinhar que Tatossian não tinha como preocupação fundamental precisar noções filosóficas ou mesmo aplicá-las em um contexto clínico. Estas surgiram e foram abordadas por ele a partir de necessidades com que foram se impondo no e pelo curso da experiência. Trata-se de uma maneira de trabalhar sempre com o fluxo de uma experiência que está sempre a aparecer, algo que Tatossian (1979/2006) defende ao longo de suas obras e que tem como fundo a compreensão sempre fenomenológica que empreende.

Para Tatossian, seria um equívoco a mera aplicação da fenomenologia, como doutrina filosófica, na psicopatologia. As diferentes noções filosóficas aparecem ao longo da experiência fenomenológica, e não como uma reflexão fenomenológica sobre a experiência, como uma espécie de contemplação. Trata-se de um posicionamento que Tatossian assume de não fechamento àquilo que de mais importante a fenomenologia considera: a experiência.

Uma influência importante de Arthur Tatossian é a de Ludwig Binswanger (1881-1966), psiquiatra suíço, apontado pelo próprio Tatossian como quem inaugura a psicopatologia fenomenológica e com quem estabeleceu um importante diálogo em termos clínicos. Mesmo com Binswanger, Tatossian assumiu uma posição crítica, reconhecendo os diferentes movimentos e aproximações de sua obra. Estes dois grandes nomes da tradição da fenomenologia clínica, de diferentes formas, construíram suas teorias e suas práticas clínicas influenciadas por Husserl e por Heidegger. Um ponto importante é que, para ambos, clínica e psicopatologia não são nomeações respectivas da prática e da teoria.

Não poderíamos deixar de mencionar a influência dos psiquiatras alemães Hubertus Tellenbach (1914-1994) e Wolfgang Blankenburg (1928-2002). Amigos próximos, Tatossian e Tellenbach mantiveram um constante diálogo, principalmente na busca da compreensão da melancolia, uma das principais contribuições de Tellenbach com a noção de Typus Melancholicus e da discussão acerca da endogeneidade na psicopatologia. Já Blankenburg teve um papel teórico fundamental ao discutir aquilo que deno- minava de experiência fenomenológica, a relação entre teoria e prática psiquiátrica e a esquizofrenia como perda da evidência natural. Tatossian dava destaque também a Blankenburg por ser quem mais teve sucesso ao tratar da questão do inconsciente na fenomenologia clínica.

Após alguns anos da morte de Tatossian, é possível apontarmos determinadas perspectivas atuais que são fruto do seu pensamento em países como a própria França, a Itália e o Brasil. Na França, alguns psiquiatras como Georges Charbonneau, Dominique Pringuey, JeanMichel Azorin, Jean Naudin, entre outros, que tiveram contato e trabalharam com a obra de Arthur Tatossian, ainda discutem e dão continuidade a discussões que foram gestadas nos anos 1990. Na Itália, onde é possível encontrar um grande número de traduções das obras de Tatossian, podemos nos remeter a Società Italiana per la Psicopatologia Fenomenologica, na pessoa do professor Riccardo Dalle Luche, que possui publicações voltadas para a psicopatologia fenomenológica de Arthur Tatossian. Neste ponto, é importante destacarmos que um dos aspectos bastante discutido atualmente tanto por estes psiquiatras franceses quanto pelos psiquiatras italianos é um olhar sobre a psicose via noção de identidade humana, recorrendo aos conceitos de mesmidade e de ipseidade, oriundos da fenomenologia hermenêutica de Paul Ricœur e presente nos últimos escritos de Tatosian.

No Brasil, destacamos o trabalho realizado pelo APHETO - Laboratório de Psicopatologia e Psicoterapia Humanista-Fenomenológica Crítica, do Programa de PósGraduação em Psicologia da Universidade de Fortaleza (Unifor) que vem desenvolvendo pesquisas e traduções da obra de Arthur Tatossian desde 2004 (Tatossian \& Moreira, 2012). Como fruto das pesquisas em torno do pensamento deste autor podemos citar os artigos "A contribuição de Tellenbach e Tatossian para uma compreensão da depressão”, (Leite \& Moreira, 2009), "Fenomenologia do tempo vivido no transtorno bipolar" (Moreira \& Bloc, 2012) e "Sintoma e fenômeno na psicopatologia fenomenológica de Arthur Tatossian” (Bloc \& Moreira, no prelo).

\section{Considerações finais}

Tatossian discutiu temáticas como esquizofrenia, paranoia, depressão, mania psicoses, alucinações e delírios, câncer, velhice, temporalidade, corpo, cultura, diagnóstico, subjetividade e clínica fenomenológica. Todas estas questões tiveram como eixo o olhar fenomenológico. Ao falarmos da psicopatologia fenomenológica de Arthur Tatossian, necessariamente tratamos de um modelo que se desenvolve a partir da clínica e para a clínica (Moreira, 2012). Há uma preocupação fundamental que se volta para o cuidado com a pessoa em sofrimento, priorizando uma comunicação compreensiva, que vai além da teorização, tendo sempre como foco a experiência. 
Ainda que existam limitações de acesso a materiais biográficos e a relatos de pessoas que conviveram com Tatossian, neste artigo foi possível apontarmos elementos históricos para a construção de um modelo de psicopatologia fenomenológica que destaca o contato fundamental com o paciente e a implicação propiciada por uma fenomenologia que o atravessa como traço marcante. A fenomenologia não pretende encontrar na historicidade de um sujeito uma via explicativa. No caso de Tatossian, poder retornar aos elementos que o constituíram como teórico e como pessoa, nos permitiu vislumbrar como se deu a construção de uma perspectiva de psicopatologia que busca sempre compreender o vivido psicopatológico e reconhece na fenomenologia a melhor via para isso.

Tatossian teve o mérito de tanto conseguir reunir em suas obras os principais representantes históricos da fenomenologia, quanto de desenvolver um modelo próprio. Seus estudos densos e instigantes, por sempre questionarem a experiência, em uma atitude fenomenológica, nos lembram constantemente que para além da teoria, há sempre alguém que precisa de cuidado e que está sofrendo. Mais do que sintetizar em um momento histórico contemporâneo o pensamento de grandes nomes da psicopatologia fenomenológica, Arthur Tatossian dá um passo adiante no sentido da constante ênfase clínica na experiência vivida.

\section{Referências}

Arditti, M. (1995). Histoire d'une amitié. La Lettre de Psychiatrie Française, 47/95, 18-19.

Azorin, J-M, Naudin, J. \& Pringuey, D. (2002). Préface. In A. Tatossian, La Phénoménologie des Psychoses (3éd., p. 9-12). Paris: Collection Phéno, Le Cercle Hermeneutique.

Bloc, L. \& Moreira, V. (no prelo). Sintoma e fenômeno na psicopatologia fenomenológica de Arthur Tatossian. Revista Latinoamericana de Psicopatologia Fundamental.

Cabestan, P. \& Dastur, F. (2011). Dasiensanalyse: Phénoménologie et psychiatrie. Paris: Librairie Philosophique J. VRIN.

Caïn, J. (1995). Pour mon ami d'exception, Arthur Tatossian. La Lettre de Psychiatrie Française, 47/95, 16-17.

Darcourt, G. (2006). Prefácio à segunda edição francesa. In A. Tatossian, A Fenomenologia das Psicoses. (J.C. Freire e V. Moreira, trads., p. 19-21). São Paulo: Escuta. (Original publicado em 2002).

Darcourt, G. \& Tatossian, J. (1997). Présentation. In A. Tatossian. Psychiatrie phénomenologique (p. 1-5). Paris: Acanthe.

Dalle Luche, R. (2003). Some essential psychopatological ideas of Arthur Tatossian (1929-1995). Comprendre, 13, 19-26.

Leite, E. \& Moreira, V. (2009). A contribuição de Tellenbach e Tatossian para uma compreensão fenomenológica da depressão. Arquivos Brasileiros de Psicologia (UFRJ), 61, 46-56.
Moreira, V. (2006). Prefácio à edição brasileira. In A. Tatossian, A fenomenologia das psicoses (J.C. Freire e V. Moreira, trads., p. 11-14). São Paulo: Escuta. (Original publicado em 1979).

Moreira, V. (março, 2009). Da empatia à compreensão do lebenswelt (mundo vivo) na psicoterapia humanista-fenomenológica. Revista Latinoamericana de Psicopatologia Fundamental, São Paulo, 12, 1, 59-70.

Moreira, V. (2011). A contribuição de Jaspers, Binswanger, Boss e Tatossian para a psicopatologia fenomenológica. Revista da Abordagem Gestáltica, Goiânia, 17, 2, 172-184.

Moreira, V. \& Bloc, L. (2012). Fenomenologia do tempo vivido no transtorno bipolar. Psicologia: Teoria e Pesquisa (Brasília. Online), 28, 17-24.

Leite, E. \& Moreira, V. (2009). A contribuição de Tellenbach e Tatossian para uma compreensão fenomenológica da depressão. Arquivos Brasileiros de Psicologia (UFRJ), 61, 46-56.

Tatossian, A. (1997). Psychiatrie phénomenologique. Paris: Acanthe.

Tatossian, A. (2006). A fenomenologia das psicoses (J.C. Freire, trad. e V. Moreira, rev. Tec.). São Paulo: Escuta. (Original publicado em 1979).

Tatossian, A. \& Azorin, J-M (1984). Phénoménologie. In A. Porot. Mannuel Alphabetique de Psychiatrie (p. 528-529). $6^{\mathrm{a}}$ ed. Paris : Presses Universitaires de France.

Tatossian, A. \& Moreira, V. (2012). Clínica do Lebenswelt (mundo vivido): Psicopatologia e Psicoterapia Fenomenológica. São Paulo: Editora Escuta.

Tatossian, J. \& Samueliam, J-C. (2006). Posfácio da segunda edição francesa. In A. Tatossian. A fenomenologia das psicoses (J.C. Freire e V. Moreira, trads., p. 347-357). São Paulo: Escuta. (Original publicado em 2002).

Lucas Guimarães Bloc - Graduado e Mestre em Psicologia pela UNIFOR. Professor efetivo do curso de Psicologia da Universidade de Fortaleza (UNIFOR) e presidente do Instituto de Psicologia Humanista e Fenomenológica do Ceará (IPHe-CE).E-mail:lucasbloc@yahoo.com.br

Virginia Moreira - Pós-Doutora em Antropologia Médica (Harvard Medical School), Professora Titular do Programa de Mestrado em Psicologia da Universidade de Fortaleza - UNIFOR e Coordenadora do Laboratório APHETO/UNIFOR. E-mail: virginiamoreira@unifor.br

Recebido em 14.01.2013

Primeira Decisão Editorial em 21.09.2013

Aceito em 25.03.2014 